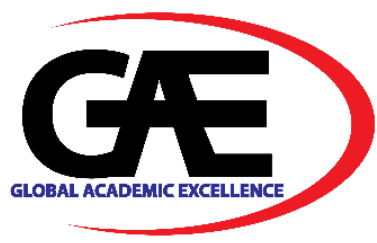

\title{
DIFFERENCES BETWEEN 2009 AND 2016 REVISIONS BASED ON COORDINATES IN GDM2000
}

\author{
Nur Adilla Zulkifli ${ }^{1 *}$, Ami Hassan Md Din ${ }^{1,2,3}$, Wan Anom Wan Aris ${ }^{3}$, Chien Zheng Yong ${ }^{3,4}$
}

1 Geospatial Imaging and Information Research Group (GI2RG), Faculty of Built Environment and Surveying, Universiti Teknologi Malaysia, 81310 Johor Bahru, Johor, Malaysia

Email: nadilla4@graduate.utm.my

2 Geoscience and Digital Earth Centre (INSTEG), Faculty of Built Environment and Surveying, Universiti Teknologi Malaysia, 81310 Johor Bahru, Johor, Malaysia

Email: amihassan@utm.my

3 Geomatics Innovation Research Group (GnG), Faculty of Built Environment and Surveying, Universiti Teknologi Malaysia, 81310 Johor Bahru, Johor, Malaysia

Email:wananom@utm.my

4 School of Surveying, University of Otago, 9013 Dunedin, New Zealand

Email: chienzheng@utm.my

* $\quad$ Corresponding Author

\section{Article Info:}

Article history:

Received date: 01.10 .2021

Revised date: 01.11 .2021

Accepted date: 20.11 .2021

Published date: 01.12.2021

\section{To cite this document:}

Zulkifli, N. A., Din, A. H. M., Aris, W. A. W., \& Chien, Z. Y. (2021). Differences Between 2009 And 2016 Revisions Based On Coordinates In GDM2000. Journal of Information System and Technology Management, 6 (24), 161-173.

DOI: $10.35631 / J I S T M .624017$

This work is licensed under CC BY 4.0

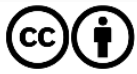

\section{Abstract:}

The Geocentric Datum of Malaysia (GDM200) is realised with respect to International Terrestrial Reference Frame (ITRF) 2000 at epoch 2nd January 2000. In comparison with the 2000 frame, ITRF2014 has significant improvement in terms of its definition and realisation. Moreover, several great earthquakes that struck the Indonesian region for the past decades have deformed the tectonic plate, resulting in a shifted GDM2000. These earthquakes, followed by post-seismic activities, has caused GDM2000 to become obsolete. Following that, the Department of Survey and Mapping Malaysia (DSMM) has taken the initiative to revise the coordinate of Malaysia Real-Time Kinematic Global Navigation Satellite Systems (GNSS) Network (MyRTKnet) stations in GDM2000 into a new set of coordinates. Therefore, this paper presents an effort to analyse the differences between coordinates in GDM2000 based on 2009 and 2016 revisions. In order to measure the discrepancy, forty-seven (47) MyRTKnet stations in Peninsular Malaysia were chosen to estimate the differences between the two (2) revisions. The coordinates obtained from MyRTKnet stations were then projected into Rectified Skewed Orthomorphic (RSO) coordinate system to compute the differences in horizontal position and ellipsoidal height. The finding showed that the discrepancy ranges from 0.8 to $11.8 \mathrm{~cm}$, with the smallest values at SETI station and the biggest value at KRAI station. Meanwhile, for the differences in ellipsoidal height, LIPI station has the biggest value of $8.1 \mathrm{~cm}$, 


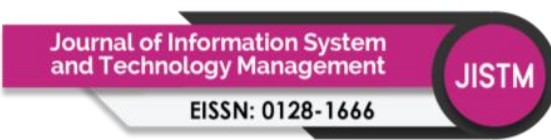

Volume 6 Issue 24 (December 2021) PP. 161-173

DOI: 10.35631/JISTM.624017

followed by the smallest value of $0.4 \mathrm{~cm}$ at SETI station. In conclusion, as the differences in revision gave impact on the changes of coordinates of MyRTKnet stations in Peninsular Malaysia, the frequent revision of GDM2000 should also consider the latest frame to give better positional accuracy, and a proper datum transformation (ITRF2014 to ITRF2000) need to be implemented for mapping purposes.

Keywords:

GDM2000, ITRF, Coordinate Revision, MyRTKnet

\section{Introduction}

A geodetic datum can be defined as a framework that best approximates the size and shape of the Earth; it is used to express the geodetic coordinate systems including a reference ellipsoid, the three (3) dimensional Cartesian system (X, Y, Z), and the well-defined parameters of translation, rotation, and scale (Mueller and Rapp, 1989; Soler and Marshall, 2002; Blick et al., 2014). Contradict against geodetic datum, a geocentric datum best approximates the size and shape of the Earth, with the origin of the coordinate systems coincides with the mass centre of the Earth or better known as Earth-centered, Earth-fixed (ECEF) (Blick et al., 2014; Bawa et al., 2019). International Terrestrial Reference Frame (ITRF) as explained by Altamimi (2009) and Altamimi et al. (2011), is a realisation of the International Terrestrial Reference System (ITRS) with a set of parameterised station positions and velocities at a reference epoch. They were estimated from a combination of Very Long Baseline Interferometry (VLBI), Lunar Laser Ranging (LLR), Satellite Laser Ranging (SLR), Global Positioning System (GPS), and Doppler Orbitography and Radiopositioning Integrated by Satellite (DORIS) individual TRF solutions. The latest frame currently developed by Altamimi is ITRF2014, with an enhanced modeling of nonlinear station motions consisting seasonal signals of station positions and post-seismic deformation for sites that were exposed to major earthquakes (Altamimi et al., 2016). These frames were continuously being improved in term of combination strategy in accordance with the latest release (Altamimi at el., 2018). Therefore, it is sensible to define contemporary frames with the current ITRF2014 rather than the previous versions, as each new ITRF solution is demonstrated to be superior to past ones (Altamimi at el., 2018).

In Malaysia, the Geocentric Datum of Malaysia 2000 (GDM2000) was realised based on ITRF2000 at epoch $2^{\text {nd }}$ January 2000 and Geodetic Reference System 1980 (GRS80) as reference ellipsoid and it was adopted by the Department of Survey and Mapping Malaysia (DSMM) to establish a countrywide global and standardised coordinate system (Shariff et al., 2014). This realisation was achieved from the zero-order geodetic network for Malaysia from the observation of fifteen (15) Malaysia Active GPS Network (MASS) and eleven (11) International Global Navigation Satellite Systems (GNSS) Service (IGS) for a period of fouryears (1999 - 2002) (Kadir et al., 2003). However, with the realisation of other frames such as ITRF2005 and ITRF2008, there is already significant diversion in origin between the two frames, not to mention ITRF2014 (QPS, 2020), resulting in GDM2000 (ITRF2000) to become less efficient to be adopted as the Earth is also dynamic.

Moreover, over the past two (2) decades, there were four (4) major earthquakes occurred in Indonesia on $26^{\text {th }}$ December 2004, $28^{\text {th }}$ March 2005, 12 ${ }^{\text {th }}$ September 2007, and $11^{\text {th }}$ April 2012 affecting displacement in Malaysia as well. Besides, after Aceh earthquake, the motion of most Sundaland block has moved towards west, from which originally before the earthquake, 
Sundaland were moved towards the east (Simons et al., 2007; Jhonny, 2010; Ramli and Samsudin, 2014; Yong et al., 2017; Yong, 2019) (refer Figure 1). Due to these events, DSMM has taken an initiative to revise GDM2000 in 2016 from the last revision in 2009 while maintaining the same ITRF and reference epoch. In addition, a new set of coordinates with respect to ITRF2014 was also introduced for processing at the central processing facility (Amiruddin et al., 2021).

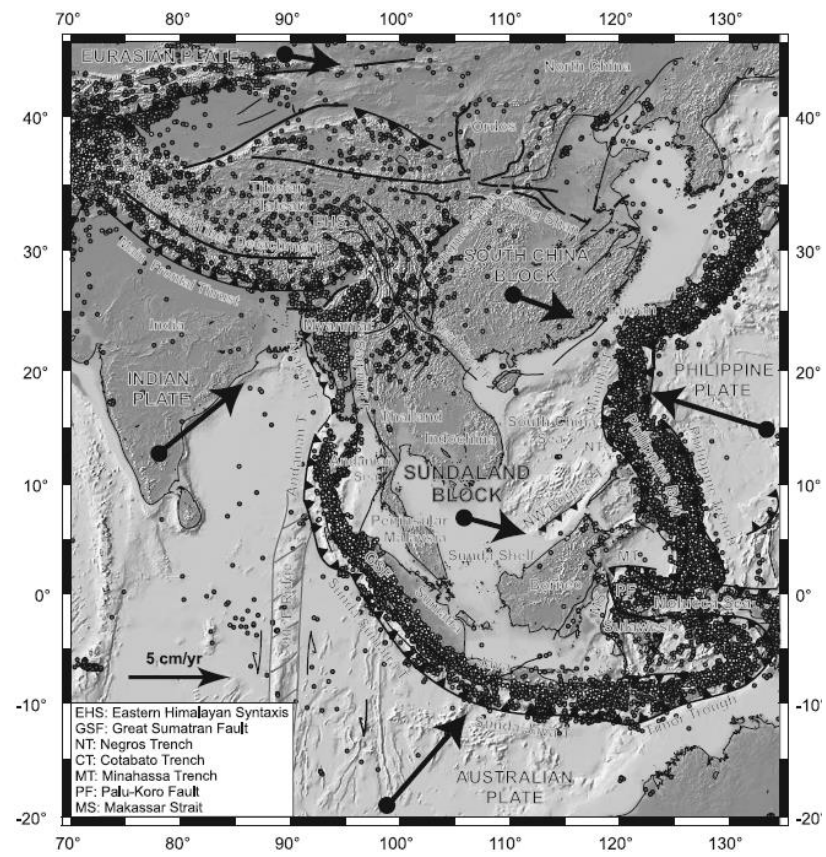

Figure 1: The Approximate Motions of Eurasian, Indian, and the South China and Sundaland Blocks

(Simons et al., 2007)

This paper analyses the differences between coordinates in GDM2000 based on 2009 and 2016 revisions. A total of forty-seven (47) MyRTKnet stations in Peninsular Malaysia were chosen and the Receiver Independent Exchange Format (RINEX) observation files of the stations were obtained in 2009 and 2016 to measure the differences between the two (2) revisions. The analysis can be done by projecting the coordinates into Rectified Skewed Orthomorphic (RSO) coordinate system to compute the differences in horizontal position and ellipsoidal height. This paper contributes findings on the changes in magnitude and direction of MyRTKnet stations, highlighting that the new revision of GDM2000 needs to consider the implementation of the latest ITRF.

\section{Data and Methodology}

\section{MyRTKnet Stations}

This study involved a total of forty-seven (47) MyRTKnet stations in Peninsular Malaysia as shown in Figure 2. These active GNSS stations which were previously known as MASS stations, were upgraded from time to time by DSMM to provide users with real-time data based on denser network covering the Malaysian region (Md Din et al., 2015; Aris, 2018). However, some stations have changes in station name as they were decommissioned (Azhari et al., 2020), hence the discontinuation in observation of the former stations. 
Volume 6 Issue 24 (December 2021) PP. 161-173

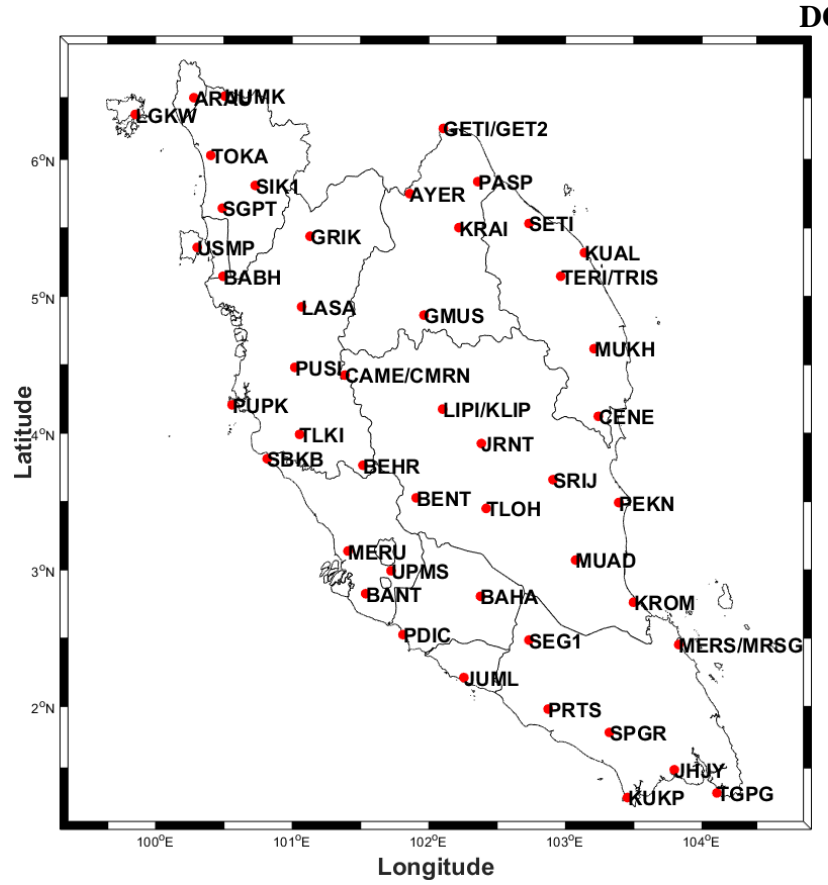
DOI: $10.35631 / J I S T M .624017$

\section{Figure 2: Distribution of MyRTKnet Stations Used in This Study}

\section{RINEX Observation Files}

Figure 3 represents the general flowchart of the methodology involved in this study, begin with data attainment until the differences in revisions were analysed. The RINEX observation files used in this study were obtained from the DSMM. From the header of RINEX observation files (refer to Figure 4), the information on the position of the stations in a three-dimensional (3D) Cartesian coordinate system (X, Y, Z) were extracted for all stations available in Peninsular Malaysia. The files were acquired for one day in 2010 representing datum revision in 2009 and another day in 2019, representing datum revision in 2016. GAJA, KLAW, and TGRH stations were excluded in this study due to data availability. The coordinate of stations with changes in station name were also acquired to assess the location of the stations. 


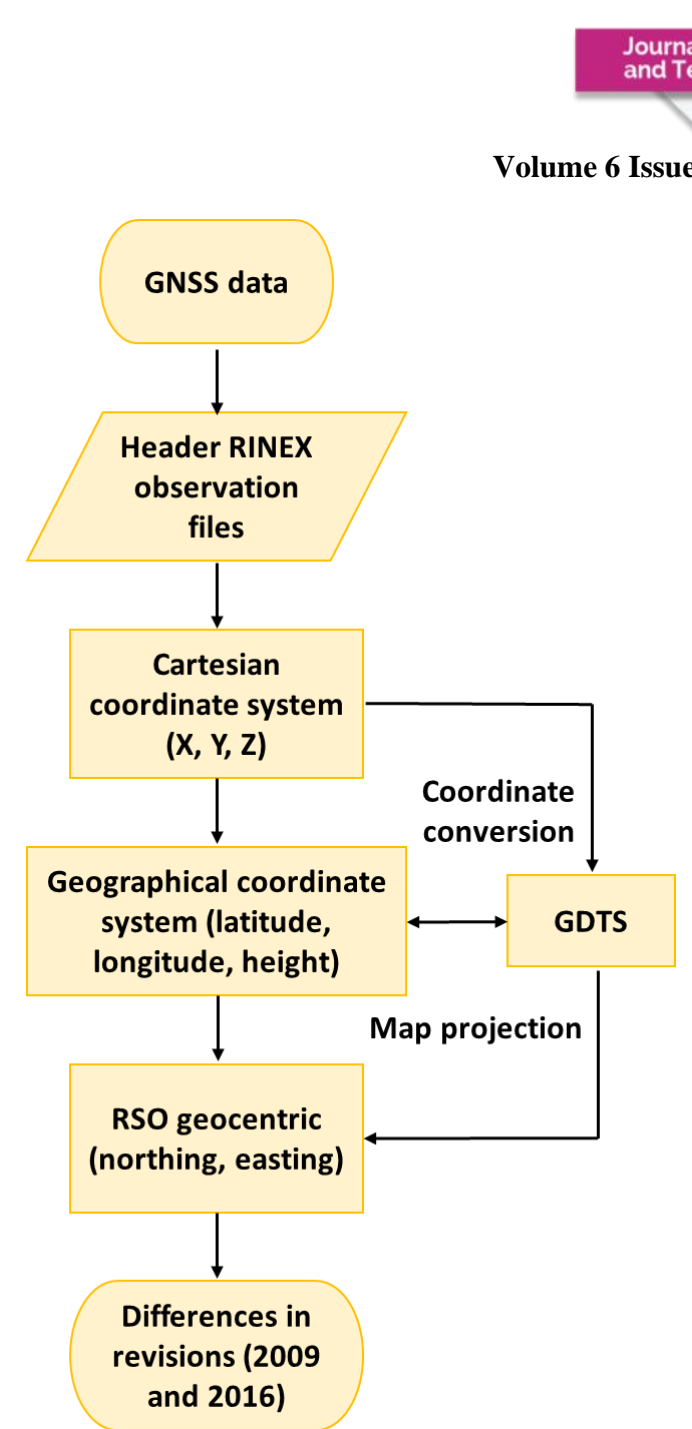

Figure 3: General Flowchart of the Methodology Involved in this study

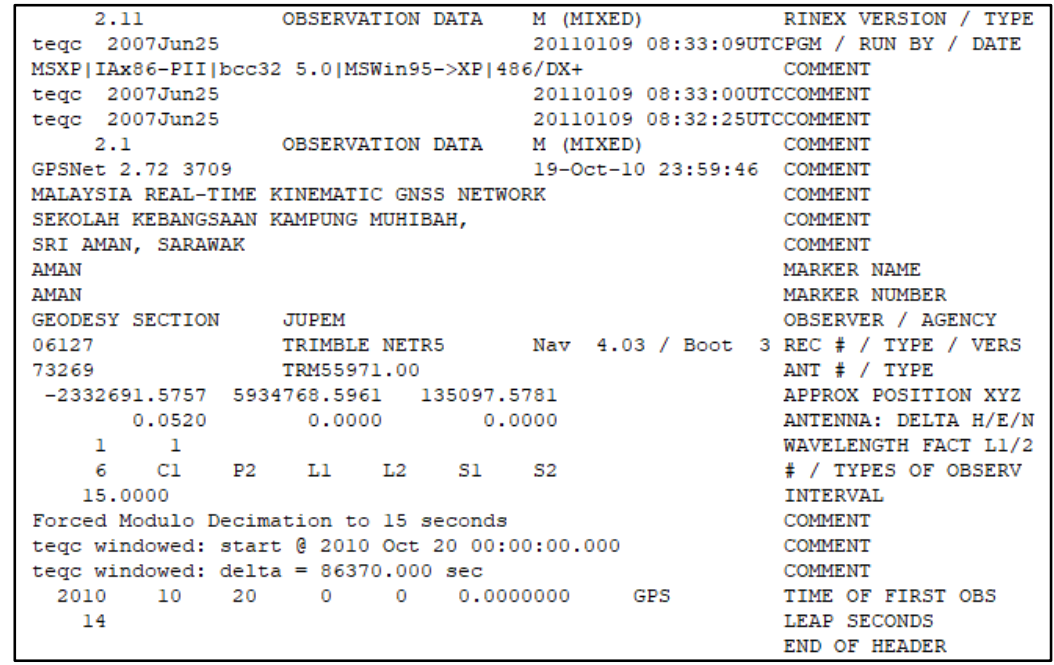

Figure 4: Sample Header of RINEX Observation File

\section{Map Projection}

The 3D Cartesian coordinate system extracted from the RINEX observation files in both revisions (2009 and 2016) were converted into a 3D geographical coordinate system in order to obtain the latitude, longitude, and ellipsoidal height. Then, from the latitude, longitude, and height of stations in GDM2000, the position was projected into a mapping coordinate system 
which is RSO geocentric (northing, easting). Both the coordinate conversion and projection were carried out using Geodetic Datum Transformation System (GDTS) Version 4.01 software (refer to Figure 5) before computing the differences between 2009 and 2016 revisions in the form of coordinates and height differences, magnitude and direction of stations.

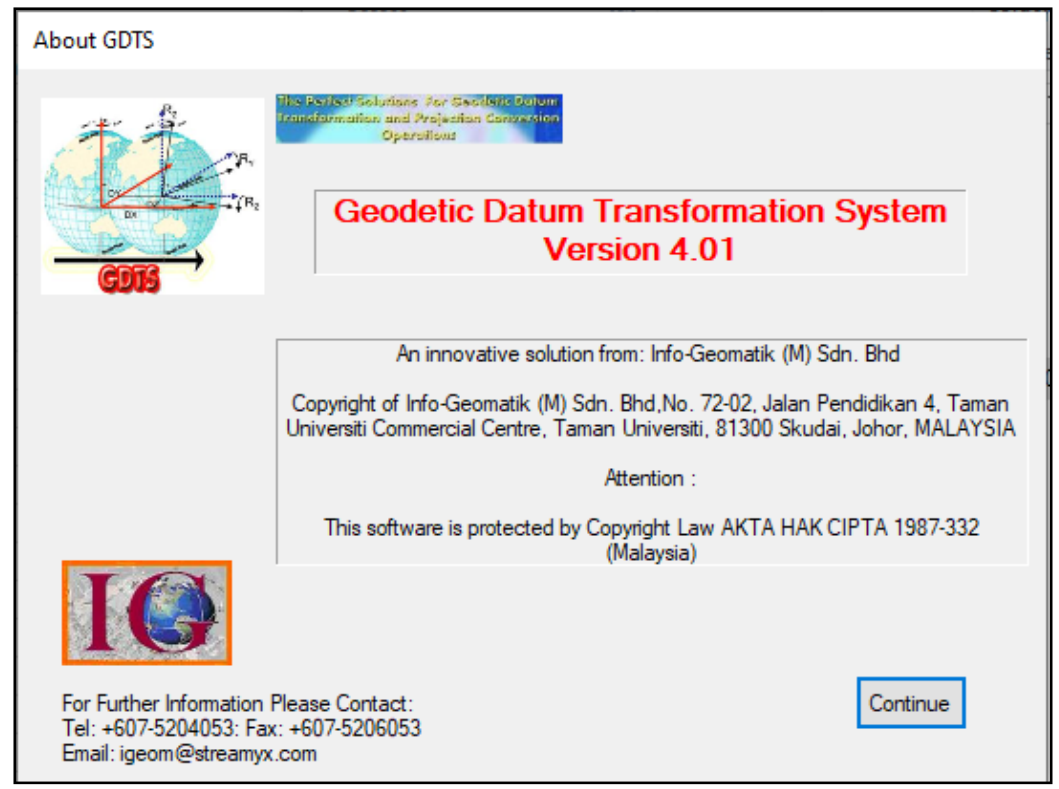

Figure 5: Geodetic Datum Transformation System Version 4.01 Software Used in this Study

\section{Results and Analysis}

\section{Differences between 2009 and 2016 Revisions}

The differences of forty-seven (47) MyRTKnet stations in Peninsular Malaysia for GDM2000 based on 2009 and 2016 revisions were computed in northing and easting direction, as well as ellipsoidal height in RSO geocentric. The results are tabulated in Table 1, with the changes in station names of CAME, GETI, LIPI, MERS, and TERI into CMRN, GET2, KLIP, MRSG, and TRIS, respectively. The differences in northing range from zero changes (ARAU and LGKW) to $24.303 \mathrm{~m}$ (GETI/GET2), followed by the easting direction from the values of 0.004 (PASP) to $34.767 \mathrm{~m}$ (GETI/GET2). Due to the remarkable differences' values between coordinate of station GETI (2009) and GET2 (2016), in northing and easting direction, both stations were treated as the exception in this study. This might probably happen due to the station relocation, where GETI and GET2 are located at two (2) different positions. For that reason, the biggest differences in northing and easting are at KRAI station, with the values of 0.048 and $0.108 \mathrm{~m}$, respectively, which may be subjected to local deformation, i.e., land subsidence (Yong et al., 2018).

Furthermore, for better illustration, the magnitude of stations between 2009 and 2016 revision are plotted in Figure 6, followed by Figure 7 for the differences in ellipsoidal height. KRAI station has the biggest displacement in vector with $0.118 \mathrm{~m}$. Meanwhile SETI station undergoes the smallest vector displacement of $0.004 \mathrm{~m}$. Besides, for the differences in ellipsoidal height, the biggest difference is noticed at LIPI/KLIP station $(0.081 \mathrm{~m})$ and the smallest difference is computed at SETI station $(0.004 \mathrm{~m})$. Since the derivation process of coordinates in 2009 and 2016 revisions is referring to the same frame and epoch (Amirrudin et al., 2021), there is no 
influence of time-dependency effect based on the physical movement. Thus, a zerodisplacement is expected between the two (2) solutions.

However, the discrepancy in northing, easting, magnitude, and direction might happen due to the physical and station-dependent effects relative to the process of coordinate derivation. The physical effects, which can be classified as systematic errors consist of displacement due to earthquake and tectonic motion. Meanwhile the station-dependent effects are the function of non-systematic errors including the changes in antenna type and height, as well as errors during GNSS data processing. Referring to the site overview of MyRTKnet stations over time, most of the antenna type has been replaced with Leica, where the stations were previously mounted with Trimble type antenna. These changes in antenna type might or might not have been taken into account for the 2016 revision. Since, the clear process of coordinate derivation based on 2009 and 2016 revisions is not being published, there are many uncertainties that could not be neglected. Therefore, Azhari et al. (2020) have taken an initiative to revise GDM2000 into a new semi-kinematic GDM2020 with respect to ITRF2014 along with the transformation parameters. Given that there is a translation rate bias in the Z-component between ITRF2000 and ITRF2014 with the value of $1.8 \mathrm{~mm} / \mathrm{yr}$, it has denoted an imprecise origin (Zulkifli et al., 2019; Yazid et al., 2019; Metivier et al., 2020).

Table 1: Differences in Northing and Easting Direction for Coordinates in RSO Geocentric (GDM2000) Based in 2009 and 2016 Revisions

\begin{tabular}{|c|c|c|c|}
\hline \multirow{2}{*}{$\begin{array}{c}\text { MyRTKnet } \\
\text { Stations (2009) }\end{array}$} & \multirow{2}{*}{$\begin{array}{c}\text { MyRTKnet } \\
\text { Stations (2016) }\end{array}$} & \multicolumn{2}{|c|}{ Differences in Revisions $(2009-2016)$} \\
\hline & & Northing $(\mathbf{c m})$ & Easting (cm) \\
\hline \multicolumn{2}{|c|}{ ARAU } & 0.0 & -5.5 \\
\hline \multicolumn{2}{|c|}{ AYER } & 3.5 & 1.8 \\
\hline \multicolumn{2}{|c|}{$\mathrm{BABH}$} & 1.2 & -0.5 \\
\hline \multicolumn{2}{|c|}{ BAHA } & 0.5 & 3.9 \\
\hline \multicolumn{2}{|c|}{ BANT } & 1.6 & 3.9 \\
\hline \multicolumn{2}{|c|}{ BEHR } & 0.9 & 2.9 \\
\hline \multicolumn{2}{|c|}{ BENT } & 0.6 & 2.1 \\
\hline CAME & CMRN & 1.0 & 1.7 \\
\hline \multicolumn{2}{|c|}{ CENE } & 1.5 & 2.7 \\
\hline GETI & GET2 & -2430.0 & -3476.7 \\
\hline \multicolumn{2}{|c|}{ GMUS } & 1.6 & 2.3 \\
\hline \multicolumn{2}{|c|}{ GRIK } & 2.2 & -0.5 \\
\hline \multicolumn{2}{|c|}{ JHJY } & -2.2 & 4.0 \\
\hline \multicolumn{2}{|c|}{ JRNT } & 0.1 & 2.0 \\
\hline \multicolumn{2}{|c|}{ JUML } & -1.1 & 5.0 \\
\hline \multicolumn{2}{|c|}{ KRAI } & 4.8 & 10.8 \\
\hline \multicolumn{2}{|c|}{ KROM } & -0.8 & 2.5 \\
\hline \multicolumn{2}{|c|}{ KUAL } & 0.6 & 2.5 \\
\hline \multicolumn{2}{|c|}{ KUKP } & -3.1 & 3.1 \\
\hline \multicolumn{2}{|c|}{ LASA } & 1.3 & 0.7 \\
\hline \multicolumn{2}{|c|}{ LGKW } & 0.0 & -6.2 \\
\hline LIPI & KLIP & 1.8 & 3.3 \\
\hline MERS & MRSG & -0.6 & 4.8 \\
\hline
\end{tabular}


MERU

MUAD

MUKH

PASP

PDIC

PEKN

PRTS

PUPK

PUSI

SBKB

SEG1

SETI

SGPT

SIK1

SPGR

SRIJ

TERI

TRIS

TLKI

TLOH

TOKA

UPMS

USMP

UUMK
2.7

$-0.3$

1.1

1.4

$-0.4$

0.9

$-2.9$

0.5

0.8

0.8

0.4

0.7

1.6

1.5

$-2.9$

$-2.0$

1.0

$-1.8$

$-0.8$

1.1

$-0.3$

1.4

0.6

0.5

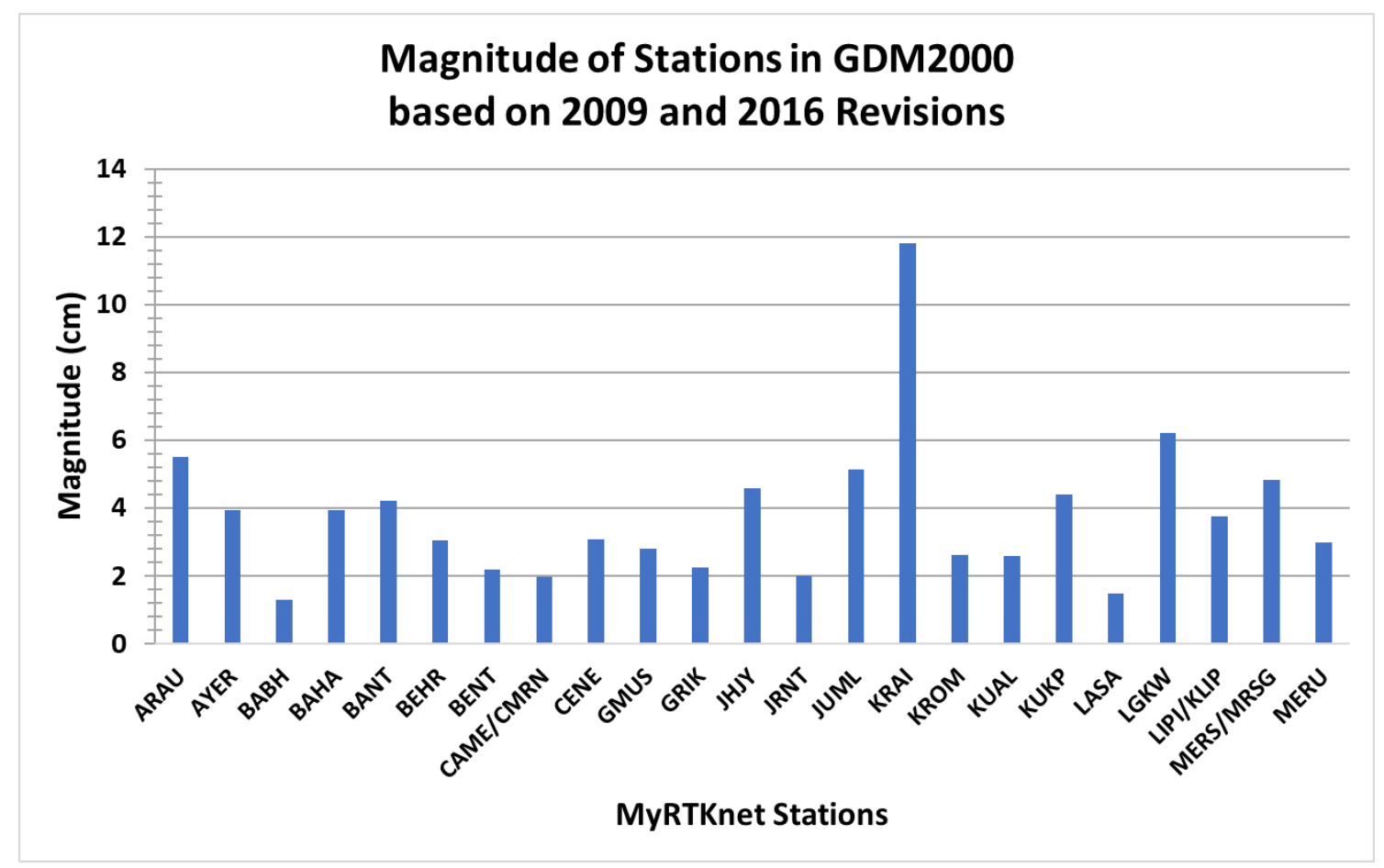

1.3

2.5

2.2

$-0.4$

2.4

4.4

0.9

1.9

1.4

2.0

2.9

0.3

$-1.6$

$-2.4$

2.4

3.9

1.7

4.0

0.9

4.1

$-5.6$

3.7

$-1.7$

$-4.0$ 


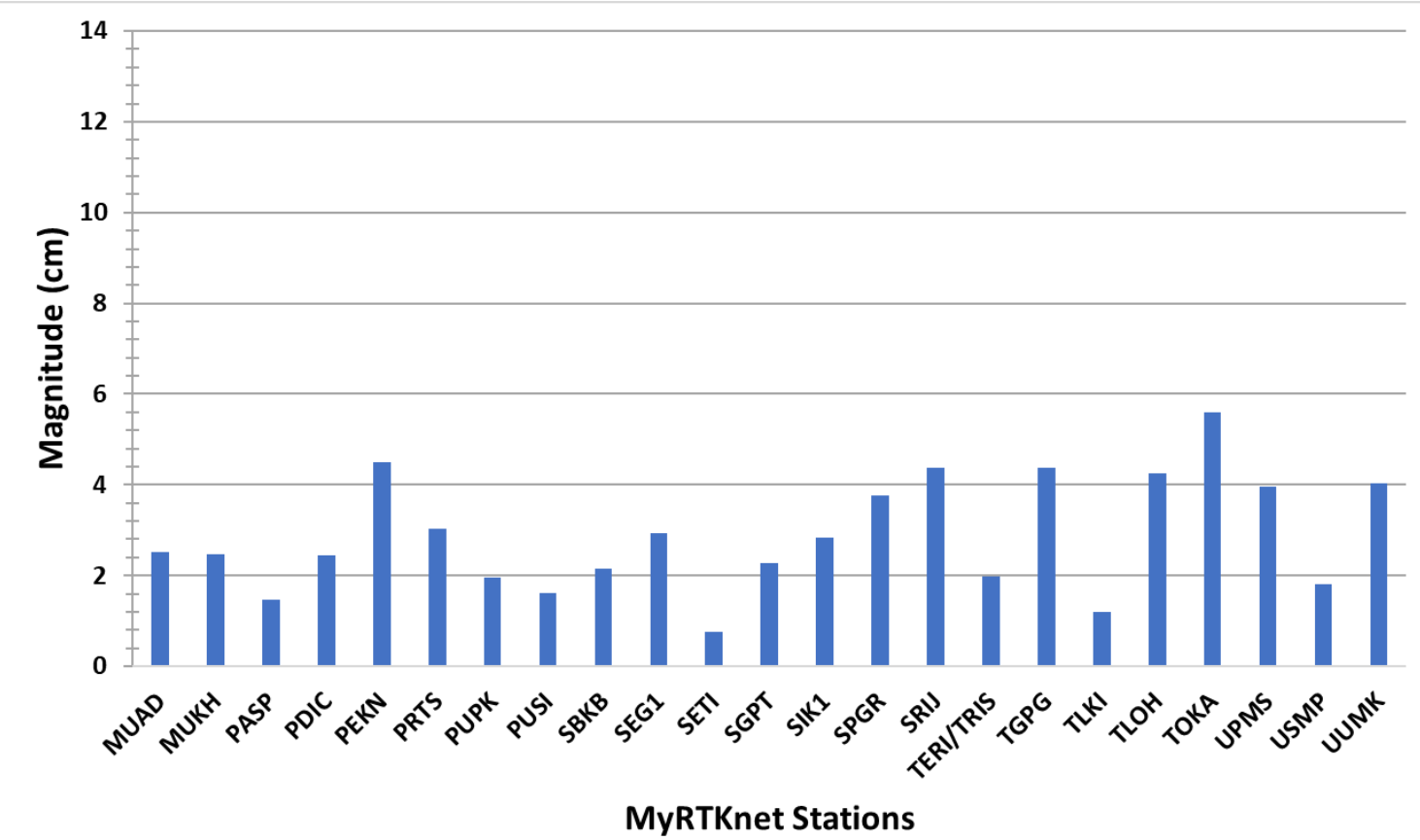

Figure 6: Magnitude of MyRTKnet Stations in GDM2000 based on 2009 and 2016 Revisions (Figure 6 Bottom is the Continuation of Figure 5 Top)

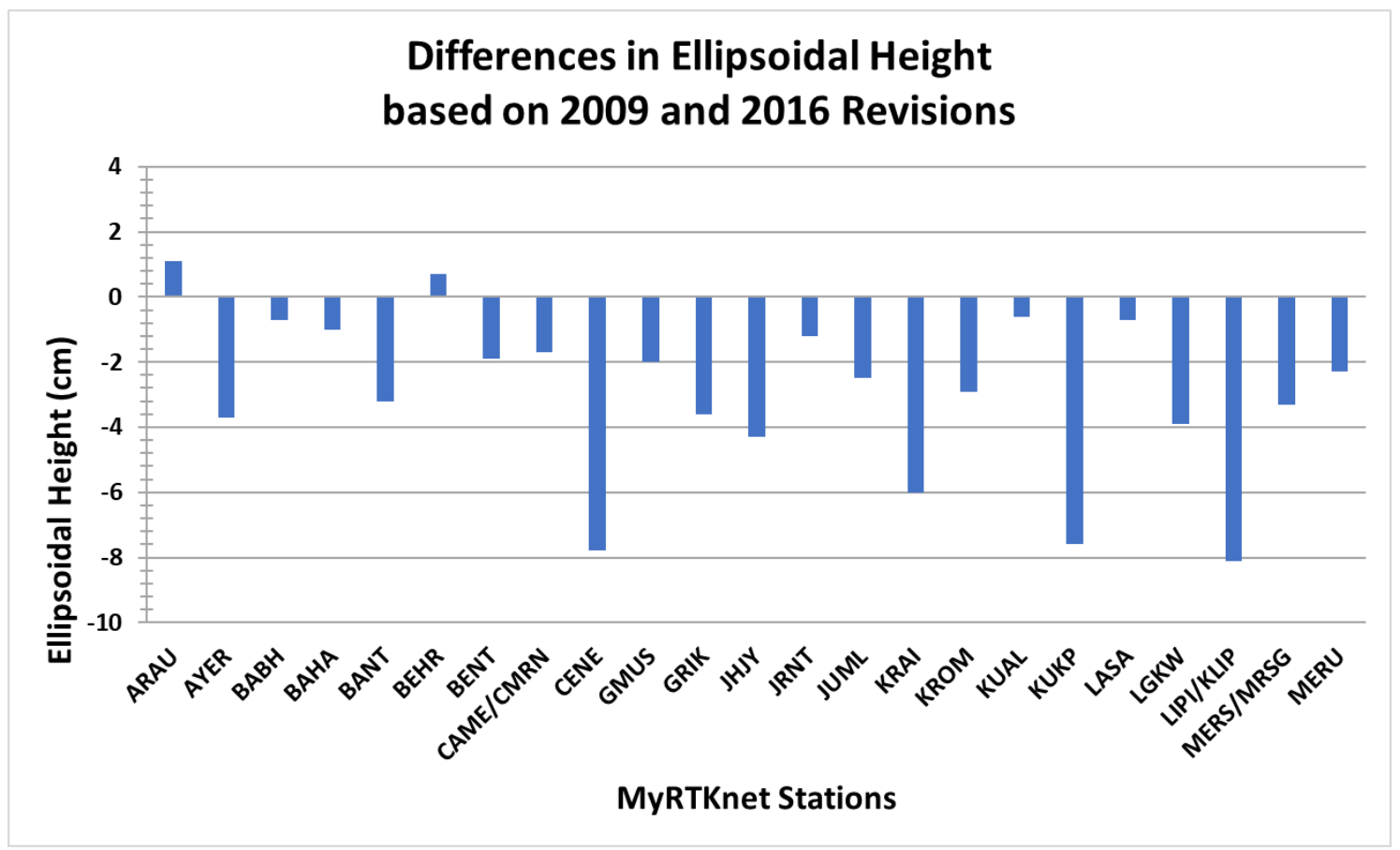




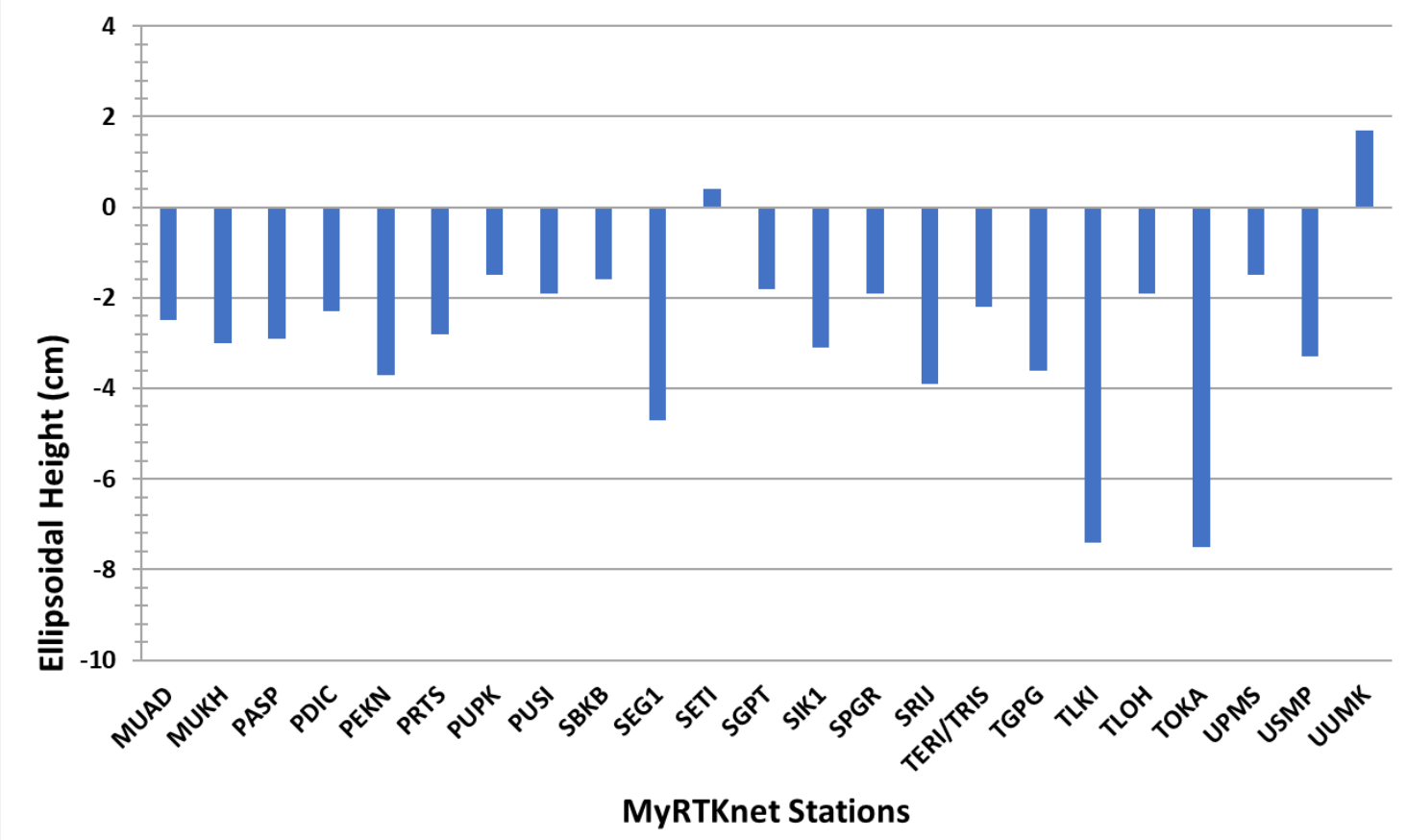

Figure 7: Differences in Ellipsoidal Height of MyRTKnet Stations in GDM2000 based on 2009 and 2016 Revisions (Figure 7 Bottom is the Continuation of Figure 7 Top)

\section{Direction of MyRTKnet Stations between 2009 and 2016 Revisions}

Figure 8 shows the direction of forty-seven (47) MyRTKnet stations in Peninsular Malaysia between coordinates in GDM2000 based on 2009 and 2016 revisions. Generally, the movement of stations can be grouped into three (3) regions: upper, middle, and lower. Referring to the upper region of Peninsular Malaysia, most of the stations project towards west-northward direction, followed by the middle region, where the stations project into east-northward direction. For the stations located in the lower region, the direction from 2009 revision is towards east-southward. Besides, MyRTKnet stations namely TLKI and SRIJ show dissimilar directions compared to the other neighbouring stations. In summation, the stations portray nonuniform pattern direction. Since there is no clear process of coordinate derivation relative to 2006 and 2016 revisions, the uncertainties correspond to the implemented parameters and model during the process of transformation as well as the sigma of the solutions become debatable. As previously mentioned in the subsection 3.1, there should only be zero differences since both revisions in 2009 and 2016 of GDM2000 were based on the same reference frame, ITRF2000 and epoch 2000.0. Therefore, the vector displacement between the two (2) revisions needs to be further evaluated as it might not be efficient enough to reflect the physical movement. However, it should be noted that, due to earthquakes and other seismic events, GDM2000 needs to be regularly updated with respect to the latest frame. 


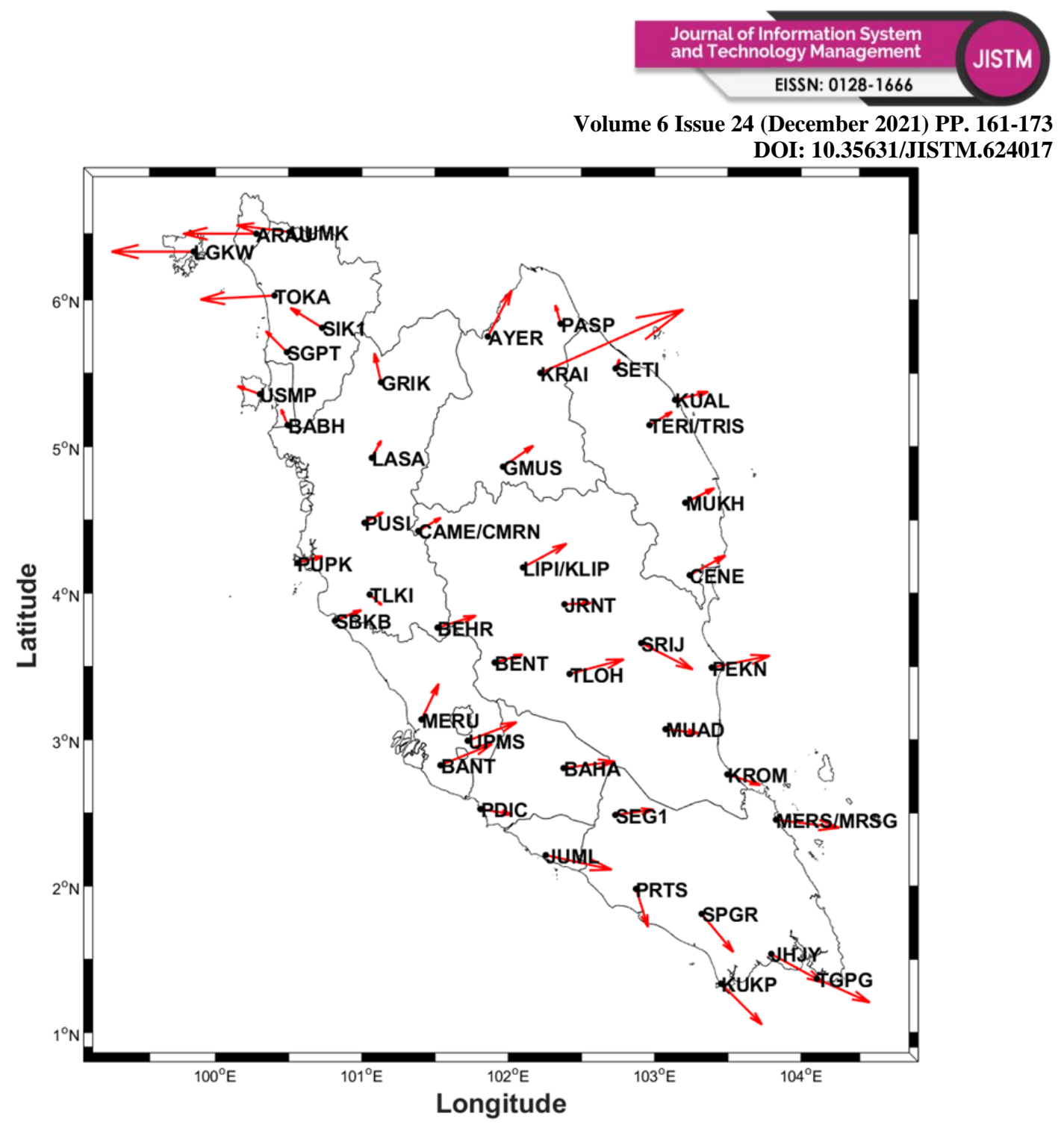

Figure 8: Direction of MyRTKnet Stations in GDM2000 from 2009 to 2016 Revisions

\section{Conclusion}

As comprehensively discussed in this paper, the differences of coordinates MyRTKnet stations in GDM2000 based on 2009 and 2016 revision initiative were successfully being estimated in Peninsular Malaysia. GETI/GET2 stations were excluded in the analysis as the enormous discrepancies in station position were likely due to the location of stations situated at different points. The results showed that the differences in magnitude of stations deviates from 0.8 (SETI) to $11.8 \mathrm{~cm}$ (KRAI), whereas for the ellipsoidal height, the smallest difference is at SETI station, followed by the biggest difference at LIPI station with the values of 0.4 and $8.1 \mathrm{~cm}$, respectively. To briefly summarise, GDM2000 based on different revisions (2009 and 2016) impacted the changes in coordinates, ellipsoidal height, and vector quantity of MyRTKnet stations in Peninsular Malaysia.

Therefore, this study recommends to regularly revise GDM2000 with respect to the latest frame, for better positional accuracy and a proper datum transformation (e.g., ITRF2014 to ITRF2000) should also be considered for mapping purposes. Further studies involving longterm data observation and processing are also suggested to better understand the coordinate derivation in GDM2000 based on the revisions in 2009 and 2016. 


\section{References}

Altamimi, Z. (2009). The International Terrestrial Reference Frame (ITRF). Fourth Meeting of the International Committee on Global Navigation Satellite System (ICG). Russian Federation: St. Petersburg.

Altamimi, Z., Collilieux, X., \& Metivier, L. (2011). ITRF2008: an improved solution of the International Terrestrial Reference Frame. Journal of Geodesy, 85(8), 457-473.

Altamimi, Z., Rebischung, P., Collilieux, X., Metivier, L, \& Chanard, K. (2018). Roadmap toward ITRF2020. Paper presented at AGU Fall Meeting, Washington DC.

Altamimi. Z., Rebischung, P., Metivier, L., \& Collilieux, X. (2016). ITRF2014: A new release of the International Terrestrial Frame modeling nonlinear station motions. Journal of Geophysical Research: Solid Earth, 121, 6109-6131.

Amirrudin, M. A., Din, A. H. M., Zulkifli, N. A., Amat, M. A. C., \& Hamden, M. H. (2021). Assessment of the accuracy and precision of MyRTKnet real-time services. Jurnal Teknologi, 83(1), 93-103.

Aris, W. A. W. (2018). Spatio-temporal crustal deformation model of Sundaland in Malaysia using Global Positioning System. (Unpublished doctoral dissertation). Universiti Teknologi Malaysia, Johor Bahru, Johor, Malaysia.

Azhari, M., Altamimi, Z., Azman, G., Kadir, M., Simons, W. J. F., Sohaime, R., Yunus, M. Y., Irwan, M. J., Asyran, C. A., Soeb, N., Fahmi, A., \& Saiful, A. (2020). Semi-kinematic geodetic reference frame based on the ITRF2014 for Malaysia. Journal of Geodetic Science, 10(1), 91-109.

Bawa, S., ojigi, L. M., Dodo, J. D., \& Lawal, K. M. (2019). Realization of time-dependent geocentric datum transformation parameters for Nigeria. Springer Nature Applied Science, 1(713), 1-10.

Blick, G., Crook, C., Donnelly, N., Fraser, R., Lilje, M., Martin, D., Rizos, C., Roman, D. R., Sarib, R., Soler, T., Stanaway, R., \& Weston, N. D. (2014). In G. Blick (Eds.), Reference frames in practice manual (pp. 1-63). Copenhagen, Denmark: International Federation of Surveyors.

Jhonny, J. (2010). Post-seismic earthquake deformation monitoring in Peninsular Malaysia using global positioning system. (Unpublished master's thesis). Universiti Teknologi Malaysia, Johor Bahru, Johor, Malaysia.

Kadir, M., Ses, S., Omar, K., Desa, G., Omar, A. H., Taib, K., Hua, T. C., Mohamed, A., Hua, C. L., Saleh, R., \& Nordin, S. (2003). Geocentric Datum GDM2000 for Malaysia implementation and implications. Paper presented at Seminar on GDM2000, Kuala Lumpur.

Md Din, A. H., Md Reba, M. N., Omar, K. M., Ses, S., \& Ab Latip, A. S. (2015). Monitoring vertical land motion in Malaysia using Global Positioning System (GPS). In M. L. Alfredo (Eds.), $36^{\text {th }}$ Asian Conference on Remote Sensing: Fostering Resilient Growth in Asia (pp. 1716-1726). Metro Manila, Philippines: Asian Association on Remote Sensing.

Metivier, L., Altamimi, Z., \& Rouby, H. (2020). Past and present ITRF solutions from geophysical perspectives. Advances in Space Research, 65(12), 2711-2722.

Mueller, I. I. \& Rapp, R. H. (1989). Horizontal and vertical geodetic datums. In J. Kovalevsky, I. I. Mueller, \& B. Kolaczek (Eds.), Reference frames (pp. 145-146). Dordrecht: Springer.

QPS (2020). Quality Positioning Service. Retrieved March 10, 2020, from https://confluence.qps.nl/qinsy/latest/en/international-terrestrial-reference-frame- 
2014-itrf2014-182618383.html\#id-

.InternationalTerrestrialReferenceFrame2014(ITRF2014)v9.1-ITRFrealizations

Ramli, S. H. \& Samsudin, A. R. (2014). Study of the movement of the western and central belts of Peninsular Malaysia using GPS data analysis. AIP Conference Proceedings, 1614(1), 750-755.

Shariff, N. S .M., Musa, T. A., Omar, K., \& Othman, R. (2014). The Geocentric Datum of Malaysia: preliminary assessment and implications. In A. A. Rahman, P. Boguslawski, F. Anton, M. N. Said, \& K. M. Omar (Eds.), Geoinformation for informed decisions (pp. 71-83). Switzerland: Springer International Publishing

Simons. W. J. F., Socquet, A., Vigny, C., Ambrosius, B. A. C., Abu, S. H., Promthong, C., Subarya, C., Sarsito, D. A., Matheussen, S., Morgan, P., \& Spakman, W. (2007). A decade of GPS in Southeast Asia: Resolving Sundaland motion and boundaries. Journal of Geophysical Research, 112(B06420), 1-20.

Soler, T. \& Marshall, J. (2002). Rigorous transformation of variance-covariance matrices of GPS-derived coordinates and velocities. GPS Solutions, 6, 76-90.

Yazid, N. M., Din, A. H. M., Abdullah, N. M., \& Omar, A.H. (2019). The implementation of modern geocentric datum: a review. The International Archives of the Photogrammetry, Remote Sensing and Spatial Information Sciences, XLII-4(W16), 685-690.

Yong, C. Z. (2019). Tectonic geodesy: an analysis of the crustal deformation of the western Sundaland plate from nearly two decades of continuous GPS measurements. (Unpublished doctoral dissertation). University of Otago, Dunedin, Otago, New Zealand.

Yong, C. Z., Denys, P. H., \& Pearson, C.F. (2017). Present-day kinematics of the Sundaland plate. Journal of Applied Geodesy, 11(3), 169-177.

Yong, C. Z., Denys, P. H., \& Pearson, C. F. (2018). Groundwater extraction-induced land subsidence: a geodetic strain rate study in Kelantan, Malaysia. Journal of Spatial Science, 64(2), 275-286.

Zulkifli, N. A., Din, A. H. M., \& Omar, A. H. (2019). The impact of different International Terrestrial Reference Frames (ITRFs) on positioning and mapping in Malaysia. In B. Pradhan (Eds.), GCEC 2017 (pp. 671-690). Singapore: Springer. 